\title{
Effect of Low Density Lipoprotein Receptor Deficiency on the Metabolism of Apolipoprotein B-100 in Blood Plasma \\ Kinetic Studies in Normal and Watanabe Heritable Hyperlipidemic Rabbits
}

Nobuhiro Yamada, David M. Shames, and Richard J. Havel

Cardiovascular Research Institute and the Department of Medicine, University of California at San Francisco, California 94143

\begin{abstract}
The kinetics of apolipoprotein (apo) B-100 in particles containing apo $\mathbf{E}$ (B,E particles) or lacking apo $\mathrm{E}$ (B particles) were studied in Watanabe heritable hyperlipidemic (WHHL) rabbits deficient in low density lipoprotein (LDL) receptors, and compared with those of normal rabbits after injection of radioiodinated very low density lipoproteins (VLDL), intermediate density lipoproteins (IDL), and LDL. In both groups results of kinetic modeling were consistent with the hypothesis that all apo $B$ enters the plasma in VLDL, mainly as B,E particles, followed by delipidation and partial conversion to IDL and LDL, with concomitant conversion of some B,E particles to B particles. In WHHL rabbits, production of VLDL apo B was reduced by $40 \%$, but LDL production was increased threefold. Defective removal of $B, E$ and $B$ particles in all three lipoprotein classes, coupled with preserved processes of delipidation, can account for the observed increases in the concentration of apo B (threefold in VLDL, fivefold in IDL, and twenty-twofold in LDL) in WHHL rabbits.
\end{abstract}

\section{Introduction}

The discovery of a mutant rabbit model of human familial hypercholesterolemia, in which low density lipoprotein (LDL) receptors are grossly deficient (the Watanabe heritable hyperlipidemic [WHHL] ${ }^{1}$ rabbit), has increased the usefulness of this species for the study of lipoprotein metabolism. In these animals, the concentration of very low density lipoproteins (VLDL) and intermediate density lipoproteins (IDL) as well as that of LDL is increased (1). Metabolic studies in WHHL rabbits have shown that the rate of irreversible disposal of VLDL (2) as well as that of $\operatorname{LDL}(3,4)$ is impaired, whereas that of chylomicrons is normal (5). As in normal rabbits virtually all apolipoprotein (apo) B100 has been shown to appear in liver perfusates of WHHL rabbits as VLDL, and the rate of accumulation of apo B is not increased in these perfusates (6). These observations, together with the finding that the fraction of VLDL converted to LDL is increased in WHHL rabbits (2), have led to several important conclusions: $(a)$ chylomicron remnants are taken up into the liver by a receptor genetically distinct from the LDL receptor;

Address correspondence to Dr. Havel, Cardiovascular Research Institute, University of California at San Francisco, CA 94143-0130.

Received for publication 31 October 1986.

1. Abbreviations used in this paper: apo, apolipoprotein; IDL, intermediate density lipoproteins; NZW, New Zealand White (rabbits); WHHL, Watanabe heritable hyperlipidemic (rabbits).

J. Clin. Invest.

(C) The American Society for Clinical Investigation, Inc.

0021-9738/87/08/0507/09 \$2.00

Volume 80, August 1987, 507-515 (b) receptor deficiency increases LDL levels by increasing LDL formation as well as by reducing its catabolism; $(c)$ the increased formation of LDL associated with receptor deficiency is not explained by increased secretion of VLDL or de novo secretion of lipoproteins of higher density, but rather by an increased fractional conversion of VLDL to LDL; and $(d)$ the LDL receptor is normally responsible for the direct uptake of VLDL remnants. These conclusions are of particular interest because the rabbit resembles the human with respect to some fundamental characteristics of lipoprotein metabolism, including the secretion of a single species of apo B (B-100) by the liver (6) and the presence of an active mechanism for transfer of cholesteryl esters and triglycerides among lipoprotein particles (7-9).

The conclusions that have been reached about the effect of LDL receptor deficiency on the metabolism of lipoproteins containing apo B-100 in rabbits have remained qualitative because methods to deal with the structural and metabolic heterogeneity of lipoproteins in this species have not been developed. We have recently reported the application of a new kinetic approach to the analysis of lipoprotein heterogeneity and its use to quantify the rate of secretion of apo B-100 and its subsequent metabolic fate in normal New Zealand White (NZW) rabbits (10). Our data indicate that all the major lipoprotein classes that contain apo B-100 are heterogeneous with respect to content of apo E, and include particles that contain apo $\mathrm{E}$ (B,E particles) as well as particles that lack apo $\mathrm{E}$ (B particles). The presence of apo $\mathrm{E}$ in VLDL particles was shown to have a major influence on the rate of irreversible disposal of component apo B and its conversion to lipoproteins of higher density, IDL and LDL.

The evident influence of apo $\mathrm{E}$ upon lipoprotein metabolism in rabbits is of particular interest because this protein, like apo $B-100$, is a ligand for the $L D L$ receptor $(11,12)$. The lack of LDL receptors should therefore influence the metabolism of $B, E$ particles as well as that of B particles.

We have carried out experiments in WHHL homozygotes, comparable with those that we have reported for NZW rabbits, to test various hypotheses concerning the influence of LDL receptor deficiency upon the metabolism of lipoproteins containing apo $\mathrm{E}$ as well as apo B-100 and to quantify the effect of receptor deficiency on rates of lipoprotein interconversions and irreversible disposal. Our results confirm previous qualitative conclusions, yield quantitative estimates of the secretion of VLDL particles and their conversion to IDL and LDL, and provide fresh insights into the nature of the kinetic heterogeneity seen in all classes of lipoproteins containing apo B. In addition, our observations suggest that some VLDL particles are removed from the blood of WHHL rabbits by high affinity mechanisms.

\section{Methods}

Animals. Male WHHL rabbits weighing 2.4-3.3 kg and male NZW rabbits weighing 2.3-2.8 kg were used for experiments in intact animals. 
All animals were fed lab rabbit chow (Ralston Purina Co., St. Louis, MO). Before and during in vivo experiments, the animals were kept in individual cages (10). For liver perfusions, two WHHL rabbits (liver weights 95 and $110 \mathrm{~g}$ ) and two NZW rabbits (liver weights 91 and $95 \mathrm{~g}$ ) were used.

Preparation of lipoproteins. The preparation of lipoproteins for experiments on NZW rabbits has been described (10). For experiments on WHHL rabbits, $10 \mathrm{ml}$ of blood was withdrawn from an ear vein 4-5 d before in vivo experiments and mixed with disodium EDTA $(1 \mathrm{mg} / \mathrm{ml})$, sodium azide $(0.2 \mathrm{mg} / \mathrm{ml})$, and gentamycin $(10 \mu \mathrm{g} / \mathrm{ml}), \mathrm{pH} 7.4$. Lipoproteins were isolated from plasma by sequential ultracentrifugation at 45,000 rpm in a Beckman ultracentrifuge $\left(50.2\right.$ rotor) at $12^{\circ} \mathrm{C}$ as follows: VLDL $(d<1.006 \mathrm{~g} / \mathrm{ml})$ for $16 \mathrm{~h}$; IDL $(1.006<d<1.109 \mathrm{~g} / \mathrm{ml})$ for 18 $\mathrm{h}$; and $\mathrm{LDL}(1.019<d<1.063 \mathrm{~g} / \mathrm{ml})$ for $20 \mathrm{~h}$. Lipoproteins used for iodination were recentrifuged at $39,000 \mathrm{rpm}$ in a 40.3 rotor at $12^{\circ} \mathrm{C}$ for $20 \mathrm{~h}$, then dialyzed against $0.15 \mathrm{M} \mathrm{NaCl}$ containing $0.01 \%$ disodium EDTA, 0.02\% sodium azide, $\mathrm{pH} 7.4$, and iodinated with ${ }^{125} \mathrm{I}$ (Pharmacia Fine Chemicals, Uppsala, Sweden) or ${ }^{131}$ I (ICN Biochemicals, Irvine, CA) by a modification of the method of McFarlane $(13,14)$ to a specific activity of $110-550 \mathrm{dpm} / \mathrm{ng}$ protein. Free iodine was removed on a column $(1 \times 10 \mathrm{~cm})$ of Sephadex G-50 (Pharmacia Fine Chemicals). As determined by assay of components separated by sodium dodecyl sulfate gel electrophoresis, at least $90 \%$ of the apo B of VLDL was in apo B100. The percentage of total radioiodine in apo $B$, measured as radioiodine insoluble in 50\% isopropranol, was 51, 83, and 79\% in VLDL, IDL, and LDL, respectively. The labeled lipoprotein (0.5-1 $\mathrm{mg}$ protein) was mixed with $1 \mathrm{ml}$ of autologous plasma and dialyzed twice against 4 liters of $0.15 \mathrm{M} \mathrm{NaCl}$ containing $0.01 \%$ disodium EDTA, $0.02 \%$ sodium azide, and gentamycin $(5 \mu \mathrm{g} / \mathrm{ml}), \mathrm{pH} 7.4$, at $4^{\circ} \mathrm{C}$. Before injection into animals, iodinated lipoproteins were dialyzed against $0.15 \mathrm{M} \mathrm{NaCl}$ for $1-2 \mathrm{~h}$ and passed through a 0.22- $\mu \mathrm{m}$ filter (Gelman Sciences, Inc., Ann Arbor, MI). VLDL were also separated from some samples of fresh plasma on a 2 $\times 90-\mathrm{cm}$ column of $6 \%$ agarose (Biogel A-5 M; Bio-Rad Laboratories, Richmond, CA) (15) to compare their composition with that of ultracentrifuged VLDL. 2 to $3 \mathrm{ml}$ of plasma was applied to the column. Elution was at $10 \mathrm{ml} / \mathrm{h}$ with $0.15 \mathrm{M} \mathrm{NaCl}$ containing disodium EDTA $(0.01 \%)$ and sodium azide $(0.02 \%)$, $\mathrm{pH} 7.4$.

Lipoprotein kinetics in vivo. For experiments in NZW rabbits, lipoproteins from donor animals were injected into recipients obtained at the same time from the supplier. For experiments with WHHL rabbits, autologous lipoproteins were used. Two lipoprotein fractions labeled with a different isotope of iodine (30-60 $\mu \mathrm{Ci}$ each) were injected simultaneously into an ear vein of unanesthetized animals at $\sim$ 9:00 a.m. Blood samples of $2 \mathrm{ml}$ were taken from an opposite ear vein into a tube containing 2 mg disodium EDTA and $0.4 \mathrm{mg}$ sodium azide 3, 30, 90, 180, 360, 720, 1,440 , and, in WHHL rabbits, $2,160 \mathrm{~min}$ after injection and placed on ice. Plaşma was separated by centrifugation at $4^{\circ} \mathrm{C}$.

Immunoaffinity chromatography. Antiserum to rabbit apo $\mathrm{E}$ was produced in a sheep (1). Specific antibodies against apo $\mathrm{E}$ were separated from $40 \mathrm{ml}$ of antiserum on a rabbit apo E-Sepharose affinity column $(1 \times 6 \mathrm{~cm})$ containing $8 \mathrm{mg}$ of apo $\mathrm{E}(16)$. The bound fraction from the column (40-140 mg of purified antibody) was coupled to CNBr-activated Sepharose 4B (Pharmacia Fine Chemicals). This immunoaffinity column $(1 \times 10 \mathrm{~cm})$, equilibrated with $0.15 \mathrm{M} \mathrm{NaCl}$ containing disodium EDTA $(0.01 \%)$ and sodium azide $(0.02 \%), \mathrm{pH} 7.4$ (buffer $\mathrm{A})$, and maintained at $4^{\circ} \mathrm{C}$, bound at least $20 \mu \mathrm{g}$ of apo E. Whole plasma $(0.02-0.1 \mathrm{ml})$ was applied to the column and the unbound material was eluted at $2 \mathrm{ml} / \mathrm{h}$ for $1 \mathrm{~h}, 20 \mathrm{ml} / \mathrm{h}$ for $30 \mathrm{~min}$, and finally $40 \mathrm{ml} / \mathrm{h}$ for $1 \mathrm{~h}$. This fraction contained no immunoassayable apo $\mathrm{E}$. The bound lipoproteins were then eluted with $\sim 30 \mathrm{ml}$ of $3 \mathrm{M}$ NaSCN containing bovine serum albumin $(1 \mathrm{mg} / \mathrm{ml}), \mathrm{pH} \mathrm{7.4}$, at a rate of $40 \mathrm{ml} / \mathrm{h}$. Columns were immediately reequilibrated with buffer $A$ and could be used several hundred times, with gradual loss of binding capacity.

Measurement of radioactivity and mass of apo $B$. Radioiodine in apo $B$ of plasma and in the fraction that did not bind to the immunoaffinity column (B particles) was measured as described $(10,17)$. Radioiodine in apo $\mathrm{B}$ of lipoproteins bound to the column (B,E particles) was determined by subtracting radioactivity in apo B of the unbound fraction from that in original whole plasma.

The concentration of apo B in VLDL, IDL, and LDL in each experimental animal was determined on pools of plasma obtained between $3 \mathrm{~min}$ and $6 \mathrm{~h}$ after uptake of radioiodinated lipoproteins. The content of radioiadine (derived from the injected ${ }^{125} \mathrm{I}$ - or ${ }^{131} \mathrm{I}$-apo B) in VLDL, IDL, and LDL separated by sequential ultracentrifugation was measured as described above. The specific activity of apo B in these fractions (which had been recentrifuged to remove contaminating plasma proteins) was determined as described (10). The concentration of apo B in each lipoprotein fraction was calculated by dividing the concentration of radioiodine in apo B by its specific activity (10).

Lipid and protein analysis. Total cholesterol and triglyceride concentrations in plasma were measured by an automated technique (18). Concentration of apo $\mathrm{E}$ in plasma and lipoprotein fractions was measured by radioimmunoassay (1).

Liver perfusion. $1-1.5 \mathrm{mCi}$ of $\left[{ }^{3} \mathrm{H}\right] \mathrm{ysine}(40 \mathrm{mCi} / \mathrm{mmol}$, Amersham Corp., Arlington Heights, IL) was injected into NZW or WHHL rabbits $30 \mathrm{~min}$ before perfusion and the liver was perfused with $3 \mathrm{mCi}$ of $\left[{ }^{3} \mathrm{H}\right]$ lysine for $30-60 \mathrm{~min}$ in a recirculating system, then flushed with nonradioactive perfusate for 3-4 $\mathrm{min}(150 \mathrm{ml})$. Perfusate was then collected for $30 \mathrm{~min}$ in a non-recirculating system and finally for an additional $30 \mathrm{~min}$ in a recirculating system (6). Samples of single-pass perfusates were applied to the anti-E affinity column and content of ${ }^{3} \mathrm{H}$ in $B$ and B,E particles was determined by liquid scintillation spectrometry in aquasol (NEN Research Products, Boston, MA). Samples of recirculating perfusates were separated by density gradient ultracentrifugation, as described below.

Density gradient centrifugation. This procedure was modified from one described previously (19). Three solutions of increasing density were layered into a Beckman centrifuge tube $(1.3 \times 6.4 \mathrm{~cm}): 2.0 \mathrm{ml}$ of water; $2.1 \mathrm{ml}$ of $0.64 \mathrm{M} \mathrm{NaCl}(d=1.025 \mathrm{~g} / \mathrm{ml}) ;$ and $2.1 \mathrm{ml}$ of $1.28 \mathrm{M} \mathrm{NaCl}(d$ $=1.050 \mathrm{~g} / \mathrm{ml}$ ). Densities of liver perfusate samples were adjusted to 1.05 and $1.025 \mathrm{~g} / \mathrm{ml}$ and used to form the lower two layers of the gradient. The sample was centrifuged in a Beckman SW 41 rotor at 39,000 rpm for $22 \mathrm{~h}$ at $12^{\circ} \mathrm{C}$. The top fraction $(0.5 \mathrm{ml})$ was obtained by tube slicing and the tube wall was rinsed with $0.5 \mathrm{ml}$ of water. Then, 11 fractions ( $0.5 \mathrm{ml} /$ fraction) were obtained sequentially by aspiration at the meniscus with an automatic pipette (Pipetman; Gilson Medical Electronics, Inc., Middleton, WI). The density of each fraction was measured with a conductivity meter and content of radioiodine in apo B was determined as above.

Kinetic analysis. Content of apo B in B,E and B particles was measured in whole plasma in six experiments each for VLDL, IDL, and LDL injections into WHHL rabbits. The averaged data were analyzed in a fashion similar to that already used in similar experiments on normal NZW rabbits (10). Briefly, this analysis took the form of first developing a model describing the kinetics of plasma B,E and B particles after LDL injection. The same analysis was again performed for injections of IDL and VLDL. By initially assuming the LDL model to be known for analysis of the IDL model and the LDL and IDL models to be known for analysis of the VLDL model, good estimates of the parameters of the three subsystems of the combined model were possible using only whole plasma B,E and B particle data. In the final parameter fitting procedure all adjustable parameters were fitted to all the data at the same time, using the time interrupt feature of the SAAM 27 program $(20,21)$.

The following additional constraints were imposed upon the modeling process to test various hypotheses relating the kinetics of apo B transport in the WHHL rabbit to those in the normal rabbit. For the WHHL model all six fractional rates of irreversible loss (from B,E and B particles in VLDL, IDL, and LDL) were initially assumed equal, the hypothesis being that apo $\mathrm{E}$ had no significant effect on irreversible loss in these animals that have little if any LDL receptor activity. This hypothesis was inconsistent with the data. The fractional rate of irreversible loss of B,E particles from VLDL had to be greater than that of the other five groups of particles; it was consequently made independently adjustable. Extravascular kinetics of B,E and B particles in LDL and IDL were 
assumed equal and invariant between normal and WHHL rabbits. This assumption was based on the fact that particle size in both density ranges in both normal and WHHL rabbits is similar (1). The fractional rates of conversion of IDL B,E particles to LDL B,E particles were assumed equal in normal and WHHL rabbits, as were the comparable rates for $B$ particles. In VLDL the fractional rates of conversion of $B, E$ and $B$ particles to IDL B,E and B particles, respectively, were assumed equal in WHHL rabbits (the hypothesis that these fractional conversion rates were the same in normal and WHHL rabbit was inconsistent with the data). The fractional rates of conversion of B,E particles to B particles in both IDL and LDL were assumed to be equal.

Two additional constraints were imposed on the model previously published for normal rabbits (10). The fractional rates of conversion of VLDL B,E and B particles to IDL B,E and B particles, respectively, were assumed equal. This hypothesis, which fit the data well, was not tested in our published model. The fractional rate of conversion of LDL B,E particles to $B$ particles was poorly determined because of the low rate of transport of both mass and radioactivity along this pathway using the model configuration adopted here (10). Since this pathway was well determined in the WHHL model, this parameter in the normal model was set equal to that in the WHHL model, a hypothesis that fitted the data well.

Of the 40 rate constants in both models, 27 were assumed dependent, leaving 13 adjustable parameters. These parameters were adjusted iteratively at the same time to the 18 sets of average tracer data (plasma $B, E, B$, and total apo B radioactivity from LDL, IDL, and VLDL injections in both normal and WHHL rabbits) using the SAAM 27 computer program. The fitting procedure was further constrained by assuming that all apo $B$ production occurs in the VLDL density range. The IDL and LDL B,E and B masses in both normal and WHHL rabbits were weighted in the steady state solution and used to constrain the fitting of the tracer data. The statistical uncertainties of the adjustable parameters were estimated from the variance-covariance matrix at the least-squares fit.

\section{Results}

Lipoprotein-lipid and protein concentrations and distributions. In this and the following section, the data from not only WHHL rabbits but also NZW rabbits, some of which have been reported previously $(1,10)$, are compared. Concentrations of lipids, apo $B$, and apo $E$ in plasma are shown in Table $I$. At the beginning and end of the experiments in WHHL rabbits, the mean plasma total cholesterol concentrations were 561 and $520 \mathrm{mg} / \mathrm{dl}$, respectively; corresponding plasma triglyceride values were 415 and $378 \mathrm{mg} / \mathrm{dl}(n=9)$. Plasma lipid values in $13 \mathrm{NZW}$ rabbits have been reported elsewhere (10). All values were manyfold higher in WHHL rabbits than in NZW rabbits, but the molar ratio of apo $E$ to apo $B$ was close to $1: 1$ in both. The content of apo $B$ and apo $E$ in ultracentrifugally separated VLDL, IDL, and LDL is shown in Table II. In WHHL rabbits the mean E/ $B$ ratio was 2.58 in VLDL, 1.23 in IDL, and 0.25 in LDL. Corresponding values for NZW rabbits were $2.25,0.56$, and 0.21 . In lipoproteins separated from two pools of plasma from WHHL rabbits by gel filtration chromatography, E/B ratios were 2.16 and 3.16 in VLDL, 0.92 and 0.87 in IDL, and 0.42 and 0.57 in LDL; corresponding values were $2.8,0.58$, and 0.32 , respectively, in one pool from NZW rabbits. Thus, for fractions separated by sequential centrifugation or gel permeation chromatography, the E/B ratio of VLDL in WHHL and NZW rabbits was similar, but in IDL the ratio was higher in WHHL than in NZW rabbits.

The concentration of apo B in lipoprotein fractions was measured in the nine WHHL rabbits used for in vivo experiments in which two labeled lipoprotein fractions were injected simultaneously (Table III). Of the $197 \mathrm{mg} / \mathrm{dl}$ of apo B in plasma, $16 \%$
Table I. Plasma Lipid and Apoprotein Concentrations in NZW and WHHL Rabbits

\begin{tabular}{lll}
\hline & NZW* & WHHL \\
\hline & $m g / d l$ & $m g / d l$ \\
Total cholesterol & $45 \pm 14$ & $561 \pm 204$ \\
Triglycerides & $77 \pm 38$ & $415 \pm 145$ \\
Apo B & $25^{* \ddagger}$ & $197 \pm 30$ \\
Apo E & $1.8 \pm 0.3$ & $10.2 \pm 2.6$ \\
Molar ratio E/B & 1.12 & 0.93 \\
\hline
\end{tabular}

Values are mean \pm SD for 8-13 animals.

* From references 1 and 10.

₹ Mean of two groups of animals $(n=6$ and $n=8)$.

${ }^{8}$ Based on $M_{\mathrm{r}}$ for apo B of 550,000 and for apo E of 34,000 .

was in VLDL, 23\% in IDL, and 60\% in LDL (values in NZW rabbits were $25 \mathrm{mg} / \mathrm{dl}$ in plasma, of which 42,37 , and $22 \%$ were in VLDL, IDL, and LDL, respectively). The concentration of apo B in B and B,E particles in each of these lipoprotein fractions was calculated from the distribution of labeled apo $B$ between $B, E$ and $B$ particles in the VLDL, IDL, and LDL injected in the kinetic experiments (Table III). This calculation was based on the observation that the specific activity of apo B in the total lipoprotein fraction and in the B particles separated by immunoaffinity chromatography differed by only $0-9 \%$. In WHHL rabbits, the percentage of apo B in B,E particles was 88 in VLDL, 88 in IDL, and 57 in LDL. Each of these values exceeded that found in NZW rabbits $(75,51$, and $15 \%$, respectively). Based upon these values for the fraction of total apo B in B,E particles and the E/B ratios found for each lipoprotein fraction (Table II), it can be estimated that the average number of apo $\mathrm{E}$ molecules in B,E particles for VLDL, IDL, and LDL, respectively, was $2.9,1.4$, and 0.44 in WHHL rabbits and 3.0, 1.1, and 1.4 in NZW rabbits. The low average number of apo $E$ molecules in B,E particles of LDL from WHHL rabbits may reflect ultracentrifugal dissociation of apo $\mathrm{E}$. This possibility is supported by the observation that the E/B ratio in LDL obtained by gel permeation chromatography from WHHL rabbits was about twice that for ultracentrifuged LDL, as noted above. Evidently, the procedure of incubating the injected lipoproteins with autologous plasma led to reacquisition of the dissociated apo $\mathrm{E}$.

Similarly, the majority, but not all, of apo B in newly secreted lipoproteins in perfusates of liver from NZW or WHHL rabbits was in B,E particles (Table IV). Virtually no labeled apo B was

Table II. Apoprotein Composition of Rabbit Plasma Lipoproteins

\begin{tabular}{|c|c|c|c|c|c|c|}
\hline & \multicolumn{3}{|l|}{ NZW } & \multicolumn{3}{|l|}{ WHHL } \\
\hline & VLDL & IDL & LDL & VLDL & IDL & LDL \\
\hline \multicolumn{7}{|c|}{ Total protein (\%) } \\
\hline Apo B & 40.9 & 72.7 & 91.3 & 46.4 & 73.9 & 84.0 \\
\hline Apo E & 5.7 & 2.5 & 1.2 & 7.4 & 5.6 & 1.3 \\
\hline \multicolumn{7}{|c|}{ Molar ratio } \\
\hline $\mathrm{E} / \mathrm{B}^{*}$ & 2.25 & 0.56 & 0.21 & 2.58 & 1.23 & 0.25 \\
\hline
\end{tabular}

Values are mean for six NZW and six WHHL rabbits.

* Based on $M_{\mathrm{r}}$ for apo B of 550,000 and for apo $\mathrm{E}$ of 34,000 . 
Table III. Concentration of apo B-100 in Plasma Lipoproteins of NZW and WHHL Rabbits

\begin{tabular}{|c|c|c|c|c|c|c|}
\hline & \multicolumn{2}{|l|}{ Total } & \multicolumn{2}{|c|}{ B,E particles } & \multicolumn{2}{|l|}{ B particles } \\
\hline & NZW & WHHL & $\mathrm{NZW}^{*}$ & WHHL ${ }^{*}$ & $\mathrm{NZW}^{*}$ & WHHL $^{\ddagger}$ \\
\hline & $m g / d l$ & $m g / d l$ & $m g / d l$ & $m g / d l$ & $m g / d l$ & $m g / d l$ \\
\hline VLDL & 10.5 & 32.5 & $7.9 \pm 1.0$ & $28.5 \pm 1.3$ & $2.6 \pm 1.0$ & $4.0 \pm 1.2$ \\
\hline IDL & 9.3 & 46.0 & $4.7 \pm 1.4$ & $40.4 \pm 2.3$ & $4.6 \pm 1.4$ & $5.6 \pm 2.2$ \\
\hline LDL & 5.5 & 118.7 & $0.8 \pm 0.27$ & $67.3 \pm 16.1$ & $4.7 \pm 0.33$ & $51.4 \pm 16.3$ \\
\hline
\end{tabular}

* Mean $\pm \operatorname{SD}(n=5-8)$.

*Mean \pm SD $(n=6)$.

found in perfusate lipoprotein fractions with densities exceeding $1.005 \mathrm{~g} / \mathrm{ml}$ in these experiments (Table V).

Lipoprotein kinetics. The kinetics of removal from whole plasma of radioiodine in total apo B injected as VLDL, IDL, and LDL are shown in Fig. 1, together with the model-generated fits to the data for both NZW and WHHL rabbits. It is clear that the rates of disappearance of apo $B$ from whole plasma of WHHL rabbits were considerably slower than those seen in NZW rabbits for all fractions injected. The rate of disappearance was greater after VLDL injection than after IDL and LDL injections in both groups. The fits of the model for NZW and WHHL rabbits to the data for B,E and B particles are shown in Figs. 2 and 3. The rates of disappearance of $B, E$ particles from plasma were faster than those of B particles for all injections, but the magnitude of differences was greater in NZW rabbits.

The rate constants $\left(h^{-1}\right)$, transports $\left(\mathrm{mg} \cdot \mathrm{dl}^{-1} \cdot \mathrm{h}^{-1}\right)$, and calculated masses $\left(\mathrm{mg} \cdot \mathrm{dl}^{-1}\right)$ for $\mathrm{NZW}$ and WHHL rabbits are shown in Figs. 4 and 5. All rate constants were well determined with fractional standard deviations $<0.10$, with the exception of the two rate constants describing extravascular kinetics. These two constants had an average fractional standard deviation of 0.19 .

The fractional rate of irreversible loss of VLDL B,E particles from plasma of WHHL rabbits was four times greater than that of VLDL B particles. However, this rate was only $\sim 10 \%$ of that for VLDL B,E particles in NZW rabbits. The fractional rates of loss of LDL B,E and B particles in WHHL rabbits were $\sim 10$ and $15 \%$, respectively, of those in NZW rabbits.

The total production rate of apo B in VLDL of WHHL rabbits was $\sim 60 \%$ of that in NZW rabbits $(4.83$ vs. 7.96 $\left.\mathrm{mg} \cdot \mathrm{dl}^{-1} \cdot \mathrm{h}^{-1}\right)$. Conversely, the production rate of LDL apo B in WHHL rabbits exceeded that of NZW rabbits by almost a

Table IV. Distribution of $\left[{ }^{3} \mathrm{H}\right]$ Lysine-labeled apo $B$ in $B$ and $B, E$ Particles in Lipoproteins of Liver Perfusates

\begin{tabular}{llllll}
\hline & NZW & & & \multicolumn{2}{l}{ WHHL } \\
\cline { 5 - 6 } Exp. & \% B & \% B,E & & \% B & \% B,E \\
\hline 1 & 32.1 & 67.9 & & 25.4 & 74.6 \\
2 & 22.9 & 77.1 & & 42.9 & 57.1
\end{tabular}

$\left[{ }^{3} \mathrm{H}\right]$ Lysine was injected into donor animals and added to perfusates, as described in Methods. Values for each experiment are means of three samples obtained after 5,10 , and 15 min of single-pass perfusions.
Table V. Distribution of $\left[{ }^{3} \mathrm{H}\right]$ Lysine-labeled apo B in Density Gradient Ultracentrifugal Fractions of Liver Perfusates

\begin{tabular}{|c|c|c|c|c|}
\hline \multirow{3}{*}{$\frac{\text { Gradient fractions }}{\text { Mean density } \pm \text { SD }}$} & \multicolumn{4}{|l|}{ Apo B } \\
\hline & \multicolumn{2}{|l|}{ NZW } & \multicolumn{2}{|c|}{ WHHL } \\
\hline & Exp. 1 & Exp. 2 & Exp. 1 & Exp. 2 \\
\hline $\mathrm{g} / \mathrm{ml}$ & $\%$ & $\%$ & $\%$ & $\%$ \\
\hline $1.0047 \pm 0.0005$ & 95.5 & 93.8 & 98.2 & 98.3 \\
\hline $1.0068 \pm 0.0006$ & 1.6 & 2.0 & 0.3 & 0.1 \\
\hline $1.0105 \pm 0.0011$ & 0.9 & 1.6 & 0.3 & 0.2 \\
\hline $1.0136 \pm 0.0009$ & 1.0 & 1.1 & 0.1 & 0.1 \\
\hline $1.0184 \pm 0.0006$ & 0.8 & 1.0 & 0.7 & 0.3 \\
\hline $1.0224 \pm 0.0007$ & 0.2 & 0.5 & 0 & 0.2 \\
\hline$>1.0275 \pm 0.0008$ & 0.1 & 0 & 0.5 & 0.8 \\
\hline
\end{tabular}

Perfusates were obtained after $30 \mathrm{~min}$ of recycling perfusion.

factor of $3\left(1.95 \mathrm{vs} .0 .67 \mathrm{mg} \cdot \mathrm{dl}^{-1} \cdot \mathrm{h}^{-1}\right)$. This increase in apo B production in LDL of WHHL rabbits, in combination with a fractional catabolic rate for LDL apo B of only $\sim 15 \%$ that found in NZW rabbits, accounts for the 22-fold increase in LDL apo B mass of WHHL rabbits as compared with that of NZW rabbits.

The calculated percentage conversions for total apo B and apo B in B,E and B particles between lipoprotein fractions are shown in Table VI. For total apo B in WHHL rabbits, $56 \%$ of VLDL was converted to IDL and $72 \%$ of IDL to LDL, yielding an overall conversion of VLDL to LDL of $40 \%$. By contrast, overall conversion of VLDL to LDL in NZW rabbits was only $8 \%$. The percentage conversion of VLDL B,E particles to LDL B,E particles was only $2 \%$ in NZW rabbits as compared with a value $>15$ times greater $(31 \%)$ in WHHL rabbits. The percentage conversions for B particles from VLDL to LDL were 29 and $74 \%$ in NZW and WHHL rabbits, respectively.

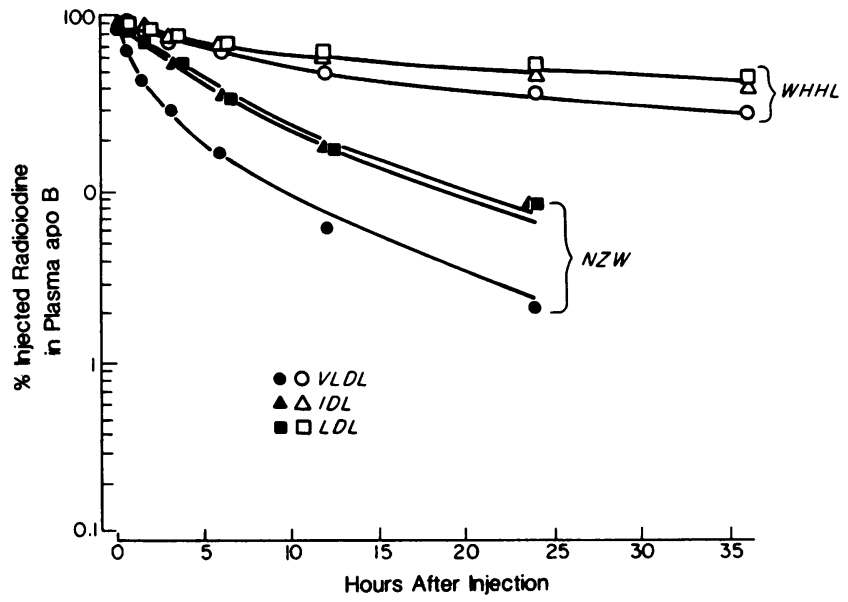

Figure 1. Removal from whole plasma of total apo B after injection of homologous radioiodinated lipoproteins into NZW rabbits and autologous radioiodinated lipoproteins into WHHL rabbits. Mean values in NZW rabbits are shown for five experiments with VLDL and eight experiments with IDL and LDL. For WHHL rabbits, mean values for six experiments with each lipoprotein fraction are shown. The curves were derived from kinetic analysis of the data using the model solutions shown in Figs. 4 and 5. 


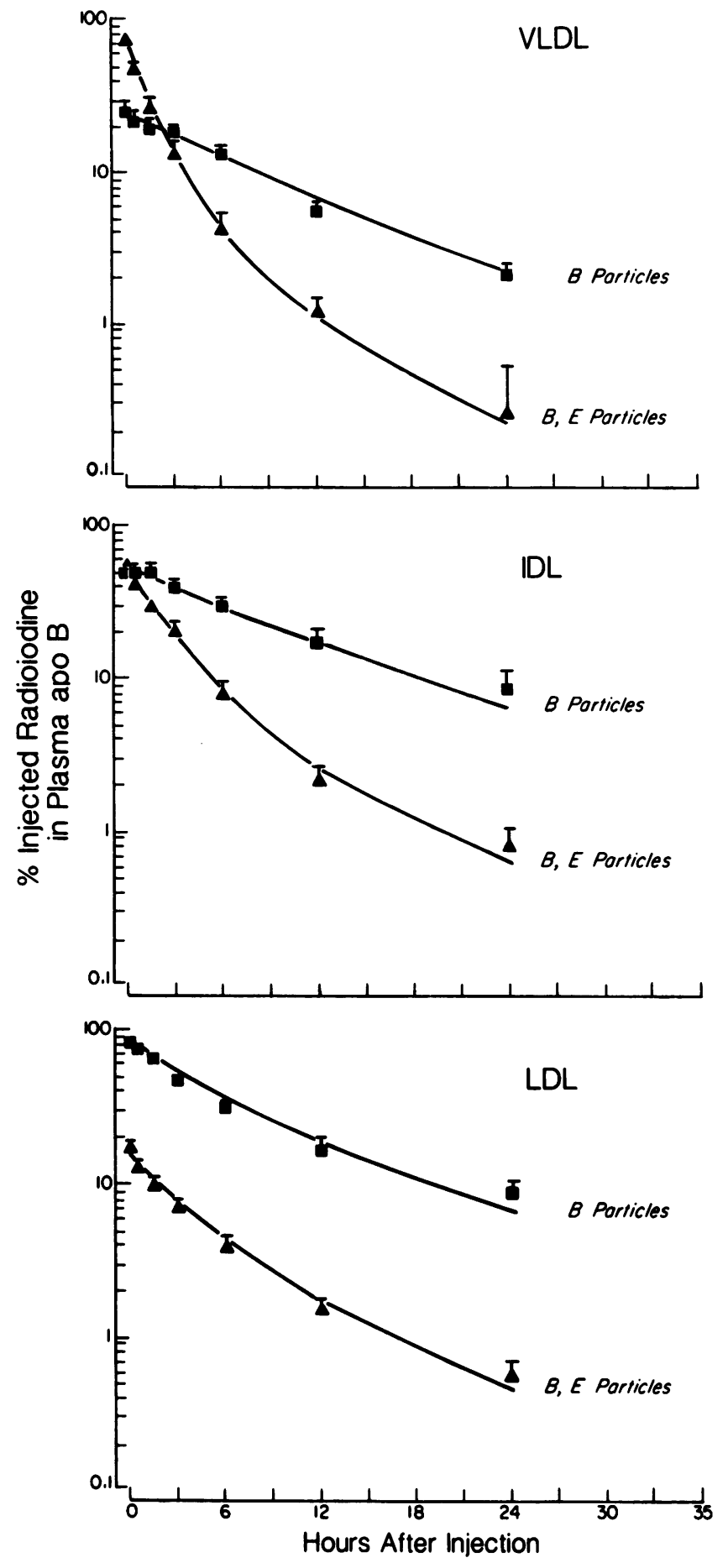

Figure 2. Removal from whole blood plasma of apo B in B,E and B particles after injection of homologous radioiodinated lipoproteins into NZW rabbits. Bars represent 1 SE (where not shown, SE values fall within data points). The curves were derived from kinetic analysis of the data using the model solution shown in Fig. 4.

\section{Discussion}

We have shown that, as in normal (NZW) rabbits (10), apo B in all major lipoprotein fractions of WHHL rabbits exists in particles that lack apo E (B particles) as well as in those that contain this protein (B,E particles). Furthermore, the presence of apo $\mathrm{E}$ influences the metabolism of VLDL particles in both groups of rabbits. Our observations confirm another basic sim- ilarity of lipoprotein metabolism in NZW and WHHL rabbitsessentially all apo $B$ is secreted in particles with a density $<1.006$ $\mathrm{g} / \mathrm{ml}$ (i.e., VLDL). Previously, it was shown that virtually all newly synthesized apo B in liver perfusates from NZW and WHHL rabbits has a density $<1.010 \mathrm{~g} / \mathrm{ml}$ (6). Our current findings, based upon density gradient ultracentrifugation of liver perfusates, indicate that $<2 \%$ of newly synthesized apo $B$ is

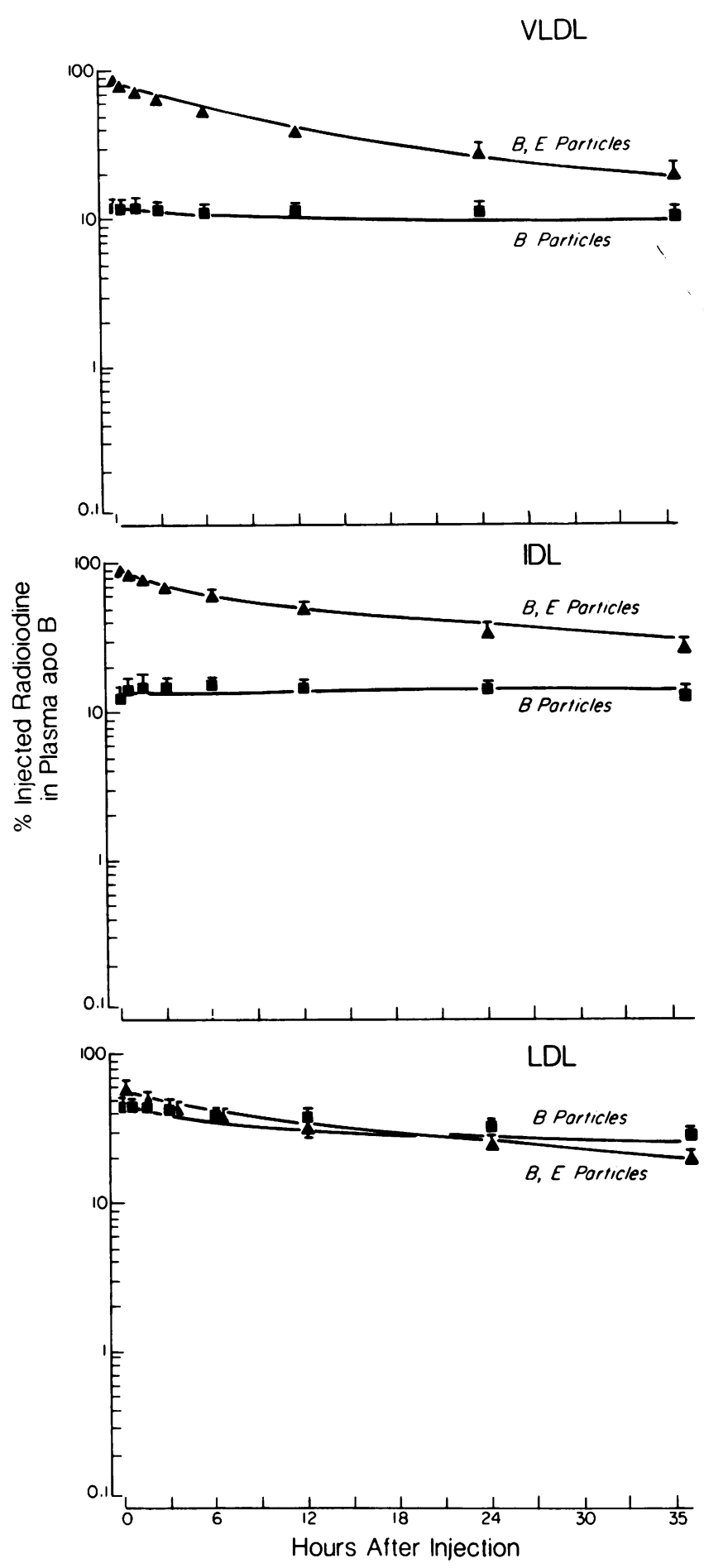

Figure 3. Removal from whole blood plasma of apo B in B,E and B particles after injection of autologous radioiodinated lipoproteins into six WHHL rabbits. Bars represent 1 SE (where not shown, SE values fall within data points). The curves were derived from kinetic analysis of the data using the model solution shown in Fig. 5. 


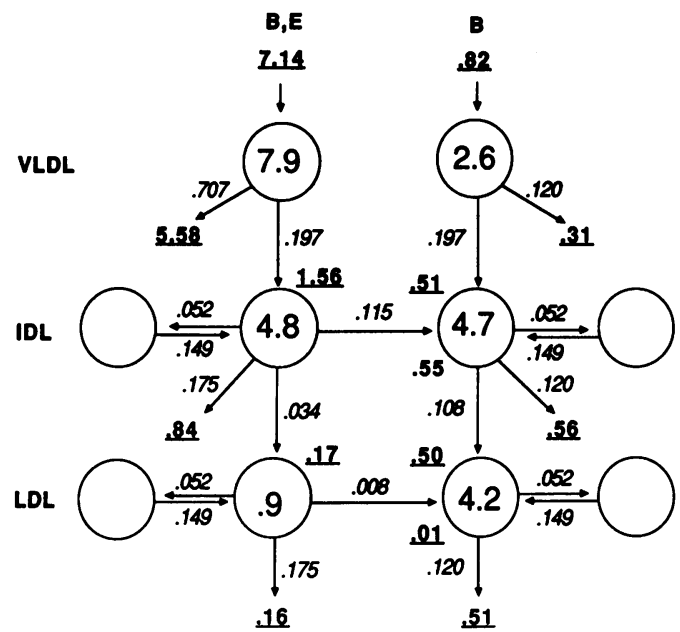

Figure 4. Multicompartmental model of the metabolism of apo B-100 in NZW rabbits: solution from analyses of data on B,E and B particles in whole plasma. The concentrations (milligrams per deciliter) of B,E and $B$ particles of lipoprotein classes in the intravascular compartment are shown within the circles. Empty circles represent extravascular compartments for IDL and LDL. Transport rates $\left(\mathrm{mg} \cdot \mathrm{dl}^{-1} \cdot \mathrm{h}^{-1}\right)$ are underlined. Small, italicized numbers are rate constants $\left(\mathrm{h}^{-1}\right)$.

secreted in particles with densities exceeding $1.005 \mathrm{~g} / \mathrm{ml}$. The apo $B$ of liver perfusates, which was contained almost exclusively in VLDL, consisted mainly of B,E particles, but like VLDL isolated from blood plasma, an appreciable fraction $(\sim 30 \%)$ of $B$ particles was also present. These perfusate particles were obtained during single-pass perfusions. However, additional experiments are required to determine the extent to which $B, E$ and $B$ particles are present in nascent VLDL within liver cells.

Although the VLDL particles produced by the liver seem to be fundamentally comparable in NZW and WHHL rabbits, their rates of removal from the blood and conversion to particles of higher density differ greatly, presumably reflecting the virtual lack of functional LDL receptors in the latter. Our analysis suggests that the rate of secretion of apo B in WHHL rabbits is

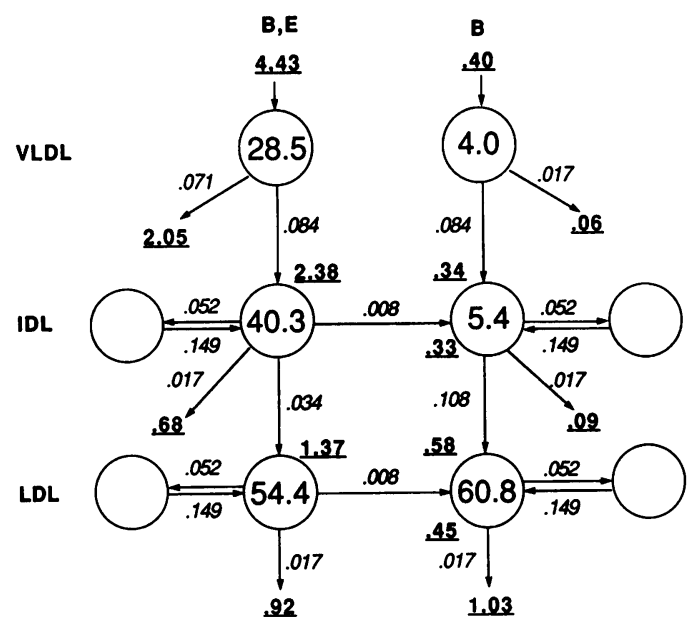

Figure 5. Multicompartmental model of the metabolism of apo B-100 in WHHL rabbits: solution from analyses of data on B,E and B particles in whole plasma. Concentrations, rate constants, and transport rates are shown as in Fig. 4.
Table VI. Conversion Percentages of apo B-100 between Lipoprotein Fractions

\begin{tabular}{|c|c|c|c|c|c|c|}
\hline \multirow{2}{*}{$\begin{array}{l}\text { Lipoprotein } \\
\text { fractions }\end{array}$} & \multicolumn{2}{|l|}{ Total } & \multicolumn{2}{|c|}{$\begin{array}{l}\text { B,E } \rightarrow \text { B,E } \\
\text { particles }\end{array}$} & \multicolumn{2}{|c|}{$\begin{array}{l}\text { B } \rightarrow \text { B } \\
\text { particles }\end{array}$} \\
\hline & NZW & WHHL & NZW & WHHL & NZW & WHHL \\
\hline VLDL $\rightarrow$ IDL & 26 & 56 & 22 & 54 & 62 & 85 \\
\hline $\mathrm{IDL} \rightarrow \mathrm{LDL}$ & 32 & 72 & 11 & 58 & 47 & 87 \\
\hline VLDL $\rightarrow$ LDL & 8 & 40 & 2 & 31 & 29 & 74 \\
\hline
\end{tabular}

lower than in NZW rabbits, despite the grossly elevated levels of apo B in all lipoprotein fractions of WHHL rabbits. Furthermore, our model solutions suggest that most apo $B$ enters plasma VLDL as B,E particles in both groups of animals, consistent with our independent observations of the properties of VLDL in liver perfusates, although the fraction of B particles in liver perfusates was somewhat higher than that predicted by the model.

The overall fractional rate of irreversible disposal of IDL as well as LDL particles was only 15\% of that observed in NZW rabbits, which suggests that $85 \%$ of these particles are normally removed by interaction with LDL receptors. This estimate exceeds the value of $\sim 70 \%$ that we $(22)$ and others $(3,4)$ have observed from analysis of rates of disappearance of radioiodine (not exclusively apo B) from whole plasma after injection of labeled LDL or methyl LDL into normal or WHHL rabbits. This discrepancy reflects the fact that our estimate of the fractional catabolic rate of LDL in WHHL rabbits is similar to that observed by others $(3,4)$, but our estimate of this rate is somewhat higher for NZW rabbits.

Our initial hypothesis that the fractional rate of irreversible disposal of apo B in VLDL of WHHL rabbits would be similar to that of IDL and LDL was not consistent with the observation that the rate of removal from whole plasma of radioiodinated apo B injected as VLDL was substantially greater than that observed after injection of IDL or LDL. We therefore considered the possibility that B,E particles in VLDL, which we found to contain an average of about three molecules of apo $E$, influenced the rate of irreversible disposal of VLDL B,E particles. This hypothesis was supported by the kinetic analysis of the whole plasma data. The fractional rate of irreversible disposal of B,E particles in VLDL of WHHL rabbits was calculated to be fourfold that of VLDL B particles, a ratio comparable with that observed in NZW rabbits.

The mechanism by which B,E particles in VLDL are removed more rapidly than B particles in WHHL rabbits is unclear. Additional experiments have shown that a small fraction of VLDL particles, whose diameter exceeds $450 \AA$, is removed rapidly from the blood of WHHL rabbits (unpublished data). VLDL of this size are also removed more rapidly from the blood of NZW rabbits, as we have observed previously in humans (23). Removal of chylomicron remnants from the blood is not impaired in WHHL homozygotes (5), and it is possible that large VLDL are recognized by the chylomicron remnant receptor. However, the mutation of the LDL receptor gene in WHHL rabbits has been shown to be of the class II variety: LDL receptors are synthesized, but are not normally glycosylated. The mutation dictates deletion of four amino acids in one of the putative receptor-binding domains of the receptor protein and it is thought that this leads to abnormal folding of the protein and greatly reduces the rate of transport from the endoplasmic reticulum to the Golgi apparatus (24). A small number of receptor mole- 
cules could reach the cell surface and function in the removal of VLDL remnants that contain several molecules of apo E (presumably in the liver). Serum and LDL cholesterol levels are reduced by compactin (25), cholestyramine (26), and partial ileal bypass (26) in WHHL homozygotes, consistent with stimulation of functional LDL receptors. However, as in untreated WHHL rabbits $(3,4)$ no receptor-mediated clearance of LDL-protein has been detected in WHHL rabbits after ileal bypass (27). In the bypassed animals, LDL-protein production was found to be reduced by $50 \%$ (27). Available evidence suggests that terminally glycosylated LDL receptors in WHHL homozygotes bind LDL poorly (28). These observations, together with those reported here, are consistent with the hypothesis that a small number of $\mathrm{LDL}$ receptors on the surface of hepatocytes may function selectively to remove large VLDL remnants, but not smaller ones or LDL in WHHL homozygotes.

Although the process by which VLDL are removed directly from the blood is grossly impaired in WHHL rabbits, the processes of delipidation by which VLDL are eventually converted to LDL seem to be intact, so that larger fractions of VLDL B,E and $B$ particles are converted to IDL and these in turn to LDL. This can account for the proportionally greater increase in the concentration of apo B in particles of increasing density (threefold in VLDL, fivefold in IDL, and twenty-twofold in LDL; see Table III). Interestingly, the model suggests that the fractional rate of conversion of VLDL to IDL was reduced in WHHL rabbits, but the further conversion of IDL to LDL seemed to proceed at the same fractional rate as in NZW rabbits, despite the much larger pool of IDL particles in WHHL rabbits. In addition, the fractional rate of conversion of IDL B,E particles to IDL B particles was much lower in WHHL than NZW rabbits. This lower rate was required in the model to account for the decreased proportion of IDL and LDL present as B particles in WHHL rabbits. Indeed, about two-thirds of all particles that contain apo $B$ are B,E particles in WHHL rabbits, including one-half of the LDL. In NZW rabbits, about one-half of particles containing apo $B$ are B,E particles, and only about one in six LDL particles contains apo $\mathrm{E}$.

Our observations confirm and extend those of Kita and associates (2), who first showed that the clearance of apo B of VLDL from whole plasma is delayed in WHHL rabbits and that it is converted to a greater extent to IDL and LDL. These observations have been interpreted to indicate that most VLDL apo B normally enters the liver as IDL, and that hepatic uptake of IDL apo B is selectively diminished in WHHL rabbits, so that a greater fraction is converted to LDL (29). Our observations indicate that hepatic uptake of VLDL apo B as well as that of IDL apo B is reduced in WHHL rabbits, so that the increased formation of LDL reflects reduced hepatic uptake of its precursor at the stage of VLDL as well as IDL (Table VI). The difference in conversion of VLDL apo B to that of IDL is most pronounced for B,E particles, which presumably reflects the high affinity of particles that contain several molecules of apo E for the LDL receptor (30-32). The data of Kita and associates have also been interpreted to indicate that IDL are normally taken up rapidly by the liver of normal rabbits (29). Our results indicate that this is not the case. Rather, IDL particles, even those that contain apo E, seem to be taken up from the blood no more efficiently than LDL. Thus, although IDL as well as VLDL may be thought of as remnants of lipolytic degradation of nascent VLDL, some property or properties of IDL make it differ from remnants of VLDL that remain within the VLDL density range. Since $B, E$ particles in IDL contain only a single molecule of apo E, whereas those of VLDL contain more than one, we suggest that VLDL remnants have higher affinity for the LDL receptor than IDL and that this accounts for their differing rates of irreversible disposal.

Our data indicate further that in spite of the virtual lack of functional LDL receptors in WHHL rabbits, not all VLDL are converted to LDL. Rather, $60 \%$ leave the plasma as VLDL or IDL. This presumably reflects the fact that receptor-independent mechanisms mediate the uptake of VLDL and IDL as well as LDL in WHHL rabbits. In addition, our data suggest that some VLDL particles are taken up by high affinity mechanisms in WHHL rabbits.

Simple inspection of the B particle tracer data resulting from LDL and IDL injections in both NZW and WHHL rabbits (Figs. 2 and 3) shows early "flatness," consistent with conversion of B,E particles to B particles. This pathway was not required for the VLDL subsystem in NZW and WHHL rabbits and for reasons of simplicity was not included in our model. Within the context of this model we tested the reverse hypothesis that B particles are converted B,E particles and found this hypothesis inconsistent with our data. This inconsistency can be appreciated in simpler terms by careful inspection of the tracer data. If both $B, E$ particle conversion to $B$ and $B$ particle conversion to $B, E$ were to exist-i.e., equilibration-both sets of tracer data should have the same final slopes, a finding clearly inconsistent with our B,E and B particle data after injection of LDL, IDL, or VLDL. $^{2}$

We conclude that the method of analysis of apo B in whole plasma that we have employed in our kinetic experiments has two advantages as compared with the usual method of separating lipoprotein fractions from recipient animals for analysis. First, it avoids problems associated with incomplete separation of lipoprotein fractions by ultracentrifugation $(10,33)$. Second, it permits straightforward analysis of heterogeneity related to the presence or absence of apo $\mathrm{E}$ in particles that contain apo $\mathrm{B}$. Although B,E and B particles can be separated from lipoprotein fractions separated in the ultracentrifuge, such particles may have been modified by ultracentrifugal dissociation of apo $\mathrm{E}$ (34-36).

Our method, however, continues to rely upon injection of lipoproteins that have been subjected to ultracentrifugal forces. We have attempted to minimize compositional alterations in the radioiodinated lipoproteins by incubating them with plasma of the recipient rabbits before injection. We have shown that the proportion of B,E and B particles in VLDL separated by gel chromatography and then radioiodinated is similar to that of ultracentrifuged VLDL, and we have found that the gel-filtered VLDL have similar kinetic properties to those of ultracentrifuged VLDL that have been incubated with autologous plasma (10). We therefore conclude that whatever the extent of ultracentrifugal dissociation of apo $\mathrm{E}$ from rabbit VLDL particles, it does not irreversibly alter their metabolic behavior.

The methods that we have developed for analysis of apo B

2. Consistent with this interpretation is the observation made in a single experiment in which VLDL-B particles were isolated from ${ }^{125}$ I-VLDL by immunoaffinity chromatography and injected into a rabbit. No labeled B,E particles could be detected in samples of whole plasma obtained during the next $24 \mathrm{~h}$. In other experiments in which labeled VLDL-B particles were mixed with whole plasma in vitro, no conversion to B,E particles was observed. 
kinetics in rabbit blood plasma should be applicable to other species. Heterogeneity with respect to presence of apo $E$ also exists in human lipoproteins that contain apo B (37-41). Therefore, our approach could yield new insights into human lipoprotein metabolism.

\section{Acknowledgments}

We thank Delia Ajoste, Sandra M. Brady, Leila Kotite, and Kyee Yeo for expert technical assistance.

This work was supported by a grant from National Institutes of Health Arteriosclerosis Specialized Center of Research (HL-14237). N. Yamada received support from the Yamanouchi Fund.

\section{References}

1. Havel, R. J., T. Kita, L. Kotite, J. P. Kane, R. L. Hamilton, J. L. Goldstein, and M. S. Brown. 1982. Concentration and composition of lipoproteins in blood plasma of the WHHL rabbit. Arteriosclerosis. 2: 467-474.

2. Kita, T., M. S. Brown, D. W. Bilheimer, and J. L. Goldstein. 1982. Delayed clearance of very low density and intermediate density lipoproteins with enhanced conversion to low density lipoprotein in WHHL rabbits. Proc. Natl. Acad. Sci. USA. 79:5693-5697.

3. Bilheimer, D. W., Y. Watanabe, and T. Kita. 1982. Impaired receptor-mediated catabolism of low density lipoprotein in the WHHL rabbit, an animal model of familial hypercholesterolemia. Proc. Natl. Acad. Sci. USA. 79:3305-3309.

4. Pittman, R. C., T. E. Carew, A. D. Attie, J. L. Witztum, Y. Watanabe, and D. Steinberg. 1982. Receptor-dependent and receptor-independent degradation of low density lipoprotein in normal rabbits and in receptor-deficient mutant rabbits. J. Biol. Chem. 275:7994-8000.

5. Kita, T., J. L. Goldstein, M. S. Brown, Y. Watanabe, C. A. Hornick, and R. J. Havel. 1982. Hepatic uptake of chylomicron remnants in WHHL rabbits: a mechanism genetically distinct from the low density lipoprotein receptor. Proc. Natl. Acad. Sci. USA. 79:3623-3627.

6. Hornick, C. A., T. Kita, R. L. Hamilton, J. P. Kane, and R. J. Havel. 1983. Secretion of lipoproteins from the liver of normal and Watanabe heritable hyperlipidemic rabbits. Proc. Natl. Acad. Sci. USA. 80: 6096-6100.

7. Zilversmit, D. B., L. B. Hughes, and J. Balmer. 1975. Stimulation of cholesterol ester exchange by lipoprotein-free rabbit plasma. Biochim. Biophys. Acta. 409:393-398.

8. Barter, P. J., and J. I. Lally. 1978. Metabolism of esterified cholesterol in the plasma very low density lipoproteins of the rabbit. Atherosclerosis. 31:355-364.

9. De Parscau, L., and P. E. Fielding. 1984. Lecithin:cholesterol acyltransferase and cholesteryl ester transfer activity from the isolated perfused rabbit liver. J. Lipid Res. 25:721-728.

10. Yamada, N., D. M. Shames, J. B. Stoudemire, and R. J. Havel. 1986. Metabolism of lipoproteins containing apolipoprotein B-100 in blood plasma of rabbits: heterogeneity related to the presence of apolipoprotein E. Proc. Natl. Acad. Sci. USA. 83:3479-3483.

11. Innerarity, T. J., R. E. Pitas, and R. W. Mahley. 1980. Receptor binding of cholesterol-induced high density lipoproteins containing predominantly apoprotein $\mathrm{E}$ in cultured fibroblasts with mutations at the low density lipoprotein receptor locus. Biochemistry. 19:4359-4365.

12. Windler, E. E. T., P. T. Kovanen, Y.-s. Chao, M. S. Brown, R. J. Havel, and J. L. Goldstein. 1980. The estradiol-stimulated lipoprotein receptor of rat liver: a binding site that mediates the uptake of rat lipoproteins containing apoproteins B and E. J. Biol. Chem. 255:1046410471.

13. McFarlane, A. S. 1958. Efficient trace labeling of proteins with iodine. Nature (Lond.). 182:53-54.

14. Sigurdsson, G., S.-P. Noel, and R. J. Havel. 1979. Quantification of the hepatic contribution to the catabolism of high density lipoproteins in rats. J. Lipid Res. 20:316-324.
15. van't Hooft, F., and R. J. Havel. 1981. Metabolism of chromatographically separated rat serum lipoproteins specifically labeled with ${ }^{125} \mathrm{I}-$ apolipoprotein E. J. Biol. Chem. 256:3963-3968.

16. Castro, G. R., and C. J. Fielding. 1984. Evidence for the distribution of apolipoprotein $\mathrm{E}$ between lipoprotein classes in human normocholesterolemic plasma and for the origin of unassociated apolipoprotein E (Lp-E). J. Lipid Res. 25:58-67.

17. Yamada, N., and R. J. Havel. 1986. Measurement of apolipoprotein $B$ radioactivity in whole blood plasma by precipitation with isopropanol. J. Lipid Res. 27:910-912.

18. Rush, R. L., L. Leon, and J. Turrell. 1970. Automated simultaneous cholesterol and triglyceride determination on the autoanalyzer II instrument. In Advances in Automated Analysis: Technicon International Congress: 1970 Clinical Analysis. Futura Publishing Co., Mt. Kisco, NY. 1:503-507.

19. Shen, M. M. S., R. M. Krauss, F. J. Lindgren, and T. M. Forte. 1981. Heterogeneity of serum low density lipoproteins in normal human subjects. J. Lipid Res. 22:236-244.

20. Berman, M., and M. F. Weiss. 1978. Simulation analysis and modeling (SAAM) users manual. In United States Department of Health, Education, and Welfare. Washington, D.C. Publication NIH:78-180.

21. Foster, D. M., and R. C. Boston. 1983. The use of computers in compartmental analysis: the SAAM and CONSAM program. In Compartmental Distribution of Radiotracers. J. S. Robertson, editor. CRC Press, Boca Raton, FL. 73-142.

22. Stoudemire, J. B., G. Renaud, D. M. Shames, and R. J. Havel. 1984. Impaired receptor-mediated catabolism of low density lipoproteins in fasted rabbits. J. Lipid Res. 251:33-39.

23. Stalenhoef, A. F. H., M. J. Malloy, J. P. Kane, and R. J. Havel. 1984. Metabolism of apolipoproteins B-48 and B-100 of triglyceriderich lipoproteins in normal and lipoprotein lipase-deficient humans. Proc. Natl. Acad. Sci. USA. 81:1839-1843.

24. Yamamoto, T., R. W. Bishop, M. S. Brown, J. L. Goldstein, and D. W. Russell. 1986. Deletion in cysteine-rich region of LDL receptor impedes transport to cell surface in WHHL rabbit. Science (Wash. DC). 232:1230-1237.

25. Watanabe, Y., T. Ito, M. Saeki, M. Kuroda, K. Tanzawa, M. Mochizuki, Y. Tsujita, and M. Arai. 1981. Hypolipidemic effects of CS500 (ML-236B) in WHHL rabbit, a heritable animal model for hyperlipidemia. Atherosclerosis. 38:27-31.

26. van Niekerk, J. L. M., T. Henbrikes, and H. H. M. de Boer. 1984. Bile acid drainage by partial small bowel bypass or cholestyramine. Effects on serum cholesterol in Watanabe heritable hyperlipidemic rabbits. Eur. Surg. Res. 16:282-287.

27. Stalenhoef, A. F. H., J. L. M. van Niekerk, P. N. M. Demacker, and A. van't Laar. 1984. Partial ileal bypass reduces the production rate of low density lipoproteins in Watanabe heritable hyperlipidemic rabbits. J. Lipid Res. 25:1350-1357.

28. Schneider, W. J., M. S. Brown, and J. L. Goldstein. 1983. Kinetic defects in the processing of the low density lipoprotein receptor in fibroblasts from WHHL rabbits and a family with familial hypercholesterolemia. Mol. Biol. Med. 1:353-367.

29. Goldstein, J. L., T. Kita, and M. S. Brown. 1983. Defective lipoprotein receptors and atherosclerosis. New Engl. J. Med. 309:288296.

30. Pitas, R. E., T. L. Innerarity, and R. W. Mahley. 1980. Cell surface receptor binding of phospholipid-protein complexes containing different ratios of receptor-active and -inactive $\mathrm{E}$ apoprotein. J. Biol. Chem. 255:5454-5460.

31. Havel, R. J. 1984. The formation of LDL: mechanisms and regulation. J. Lipid Res. 25:1570-1576.

32. Havel, R. J. 1985. Role of the liver in atherosclerosis. Atherosclerosis. 5:569-580.

33. Packard, C. J., A. Munro, A. R. Lorimer, A. M. Gotto, and J. Shepherd. 1984. Metabolism of apolipoprotein B in large triglyceriderich very low density lipoproteins of normal and hypertriglyceridemic subjects. J. Clin. Invest. 74:2178-2192.

34. Fainaru, M., R. J. Havel, and K. Imaizumi. 1977. Apoprotein 
content of plasma lipoproteins of the rat separated by gel chromatography or ultracentrifugation. Biochem. Med. 17:347-355.

35. Havel, R. J., L. Kotite, J.-L. Vigne, J. P. Kane, P. Tun, N. Phillips, and G. C. Chen. 1980. Radioimmunoassay of human arginine-rich apolipoprotein, apoprotein E. Concentration in blood plasma and lipoproteins as affected by apoprotein E-3 deficiency. J. Clin. Invest. 66:13511362.

36. Fielding, C. J., G. M. Reaven, G. Liu, and P. E. Fielding. 1984. Increased free cholesterol in plasma low and very low density lipoproteins in non-insulin-dependent diabetes mellitus: its role in the inhibition of cholesteryl ester transfer. Proc. Natl. Acad. Sci. USA. 81:2512-2516.

37. Kane, J. P., T. Sata, R. L. Hamilton, and R. J. Havel. 1975. Apoprotein composition of very low density lipoproteins in human serum. J. Clin. Invest. 56:1622-1634.
38. Pagnan, A., R. J. Havel, J. P. Kane, and L. Kotite. 1977. Characterization of human very low density lipoproteins containing two electrophoretic populations. Double pre-beta lipoproteinemia and primary dysbetalipoproteinemia. J. Lipid Res. 18:613-622.

39. Shelburne, F. A., and S. H. Quarfordt. 1977. The interaction of heparin with an apoprotein of human very low density lipoprotein. $J$. Clin. Invest. 60:944-950.

40. Trezzi, E., C. Calvi, P. Roma, and A. L. Catapano. 1983. Subfractionation of human very low density lipoproteins by heparinSepharose affinity chromatography. J. Lipid Res. 24:790-795.

41. Fielding, P. E., and C. J. Fielding. 1986. An apo E-free very low density lipoprotein enriched in phosphatidylethanolamine in human plasma. J. Biol. Chem. 261:5233-5236. 